\title{
Overview of Machine Translation Development
}

\author{
Irene Rivera-Trigueros \\ (iD) https://orcid.org/0000-0003-4877-4083 \\ Department of Translation and Interpreting, University of Granada, Spain \\ María-Dolores Olvera-Lobo \\ (iD) https://orcid.org/0000-0002-0489-7674 \\ Department of Information and Communication Sciences, University of Granada, Spain \\ Juncal Gutiérrez-Artacho \\ (iD) https://orcid.org/0000-0002-0275-600X \\ Department of Translation and Interpreting, University of Granada, Spain
}

\section{INTRODUCTION}

Information is increasingly global, which brings with it the growth in a non-English speaking public and, as such, a demand for tools that allow users to access this information. Faced with this scenario, the development of new tools and technologies is a key element. This is the case of Machine Translation (MT), one of the most popular and used tools to overcome linguistic barriers. As a result, linguistic companies are increasingly offering services related to MT as, in many cases, it is impossible to meet the demand for translations only with human translators. In addition, MT systems can be integrated with other tools and resources such as Translation Memories-databases which store already translated text for future use - or multilingual terminology databases - also known as glossaries-in order to improve the efficacy of the translation process.

In this chapter an overview of MT development since its early beginnings in the late 1950s until the present day is proposed. The evolution of MT techniques will be reviewed starting from the traditional approaches - Statistical and Rule-Based MT — and finishing with the latest trends, which include hybrid MT systems, Adaptive MT and Neural MT.

\section{BACKGROUND}

\section{Brief History of Machine Translation}

The origins of Machine Translation date back to the 17th century, as during this time an interest for creating an universal language based on logic principles and iconic symbols and for developing mechanical dictionaries arises (Hutchins, 2007). During the following centuries, there were some proposals to create international artificial languages, among which stood out Esperanto (Hutchins, 1995; HernándezMercedes, 2002). However, there were no real attempts for automating translation until 1933, when two patents were issued for machines functioning as multilingual mechanical dictionaries, designed to find

DOI: 10.4018/978-1-7998-3479-3.ch060 
the equivalent of a word in another language. One patent was issued in France, to Georges Artsouni, and the other one in Russia, to Petr Trojanskij. During the 1940s Andrew Booth and Warren Weaver developed the first ideas which involved computers for translating natural languages and worked with Richard H. Richens on morphological analysis for a mechanical dictionary (Hutchins, 1995).

In 1951 Yehoshua Bar-Hillel, from the Massachusetts Institute of Technology (MIT), outlined some of the basic approaches to MT in a state-of-the-art-report and one year later the first MT conference was held at MIT. The conference evidenced that good quality MT was not possible, as long-term research was needed. Therefore, at that stage, human intervention was required before (pre-editing) or after (post-editing) the process. In addition, during the conference it was also highlighted that a public demonstration was necessary in order to attract funding (Hutchins, 2007; Hernández-Mercedes, 2002). Two years later, in 1954, the first public demonstration of an MT system was carried out as a result of a joint project between IBM and Georgetown University. Despite not having a remarkable scientific value, this demonstration was the starting point for large-scale funded MT research in the USA and for the developing of MT projects around the world, especially in the USSR (Hutchins, 1995).

During the following ten years, there were two main approaches regarding MT research. On the one hand, empirical approaches focused on statistical methods in order to discover grammatical and lexical regularities. On the other hand, theoretical approaches were based on linguistic research, which led to the beginnings of computational linguistics (Hutchins, 2007).

Even though during this decade research on MT field seemed promising, the linguistic and semantic problems became more and more noticeable. Therefore, the National Science Foundation was asked by government sponsors in the USA to assess future prospects of MT. For this purpose, the Automatic Language Processing Advisory Committee (ALPAC) was formed in 1964. The ALPAC report in 1966 pointed out that MT was slower, less accurate and twice as expensive as human translation. Consequently, the ALPAC report meant a significant reduction in MT research and development (Dorr, Jordan, \& Benoit, 1999). Despite the impact of the ALPAC report, some research groups at the University of Texas and at Wayne State University continued researching on MT in the USA, which were focused on translating scientific and technical materials from Russian into English (Hutchins, 2007). However, between 1967 and 1977, MT research was carried out mainly in Canada and Europe. There was a high demand for English-French translations in Canada due to its bicultural policy. For its part, in the European Community, it was necessary to translate scientific, technical, administrative and legal documentation into all the languages of the European Community. During the decade of 1970, at Montreal, researches of the TAUM project (Traduction Automatique de l'Université de Montréal) designed Méteo, a system for translating weather forecast (Dorr et al., 1999). During the same years, the European Community purchased an MT system called Systran-developed by Peter Tomas-and, at the end of the 1970s, decided to establish a research project called EUROTRA, whose aim was to create an MT system for all the official languages of the European Community (Alcina Caudet, 2011).

In the 1980s, Systran continued to evolve and include more languages while new systems such as LOGOS or METAL entered the market. Special-purpose MT systems-designed for particular environments-were also developed. That was the case of SPANAM and ENGSPAN, two systems developed by the Pan American Health Organization (Hutchins, 2007).

During the 1980s, research groups continued working on MT. For instance, the GETA (Groupe d'Études pour la Traduction Automatique) group developed the Ariane system, which influenced MT projects around the world. In 1986, the research prototype of the Mu system, which was conceived at the University of Kyoto, became an operational system used by the Japanese Information Center for Science and Technology. This project influenced Japanese computer companies, which started to invest 
11 more pages are available in the full version of this document, which may be purchased using the "Add to Cart" button on the product's webpage: www.igi-global.com/chapter/overview-of-machine-translationdevelopment/260236?camid $=4 \mathrm{v} 1$

This title is available in e-Book Collection, Communications, Social Science, and Healthcare e-Book Collection, Computer Science and Information Technology e-Book Collection, Media and Communications e-Book Collection, Science, Engineering, and Information Technology e-Book Collection, Computer Science and IT Knowledge Solutions e-Book Collection, Advances in Information Quality and Management, Social Sciences Knowledge Solutions e-Book Collection, Evidence Based Acquisition, e-Book

Collection Select, E-Access. Recommend this product to your librarian: www.igi-global.com/e-resources/library-recommendation/?id=1

\section{Related Content}

Understanding and Assessing Quality of Models and Modeling Languages

John Krogstie (2018). Encyclopedia of Information Science and Technology, Fourth Edition (pp. 48104821).

www.igi-global.com/chapter/understanding-and-assessing-quality-of-models-and-modelinglanguages $/ 184185$ ?camid=4v1a

Load Flow Analysis in Smart Grids

Osman Hasan, Awais Mahmood and Syed Rafay Hasan (2018). Encyclopedia of Information Science and Technology, Fourth Edition (pp. 3103-3113).

www.igi-global.com/chapter/load-flow-analysis-in-smart-grids/184022?camid=4v1a

Hybrid Data Mining Approach for Image Segmentation Based Classification

Mrutyunjaya Panda, Aboul Ella Hassanien and Ajith Abraham (2016). International Journal of Rough Sets and Data Analysis (pp. 65-81).

www.igi-global.com/article/hybrid-data-mining-approach-for-image-segmentation-basedclassification $/ 150465$ ?camid $=4 \mathrm{v} 1 \mathrm{a}$

Enhancement of TOPSIS for Evaluating the Web-Sources to Select as External Source for WebWarehousing

Hariom Sharan Sinha (2018). International Journal of Rough Sets and Data Analysis (pp. 117-130). www.igi-global.com/article/enhancement-of-topsis-for-evaluating-the-web-sources-to-select-asexternal-source-for-web-warehousing/190894?camid=4v1a 